\title{
Diversity of antibiotics in hospital and municipal wastewaters and receiving water bodies and removal efficiency by treatment processes: a systematic review protocol
}

\author{
Seyedeh Masoumeh Ebrahimi ${ }^{1}$, Reza Dehghanzadeh Reyhani ${ }^{* *}$ (1), Mohammad Asghari-JafarAbadi² \\ and Zahra Fathifar ${ }^{3}$
}

\begin{abstract}
Background: Antibiotics are extensively discharged into the environment through sewages. These emergent contaminants cause health and environmental risks by toxicity, allergic impacts, non-biodegradability and more importantly advancing antibiotic resistance. Antibiotics are hardly removed by conventional treatment processes and frequently are being reported in aquatic environments. The systematic review outlined in this protocol will compile and synthesize literature on the variety and concentrations of antibiotics in wastewaters and receiving water resources. Also, the review will address the efficiency of treatment processes in elimination of antibiotics from aqueous solutions. Outcomes of the study could help wastewater treatment plant engineers with providing reliable design data and outline a road map for future researches.

Methods: The review will be performed according to the Collaboration for Environmental Evidence (CEE) guidelines for systematic review and evidence synthesis in environmental management, and will be reported according to ROSES reporting standards for systematic evidence syntheses. The published articles will be screened by considering the defined inclusion and exclusion criteria at the title, abstract and full-text levels. Included studies will be exposed to a critical appraisal for validity and quality assessment. The articles will be assessed on the susceptibility to bias and the studies with high bias will be excluded from the data synthesis. The data from included studies will be combined into a narrative synthesis. Random effect Meta-analysis will be conducted due to the likely range of underlying effects. If the heterogeneity exists, the source of heterogeneity will be sought by met-regression and subgroup analyses.
\end{abstract}

Keywords: Review, Protocol, Antibiotic, Pharmaceutical, Wastewater, Sewage, Hospital, Municipal, Removal efficiency

\section{Background}

Hospital wastewaters are one of the most toxic divisions of municipal wastewaters due to containing numerous hazardous and emergent micro-pollutants such as pharmaceuticals, heavy metals, adsorbable organic halogens,

*Correspondence: dehghanzadehr@tbzmed.ac.ir

${ }^{1}$ Health and Environment Research Center, Tabriz University of Medical Sciences, Tabriz, Iran

Full list of author information is available at the end of the article iodized X-ray contrast media, cytostatic agents, residual of chemical compounds used in laboratories, disinfectants, radioisotopes, and also variety of pathogenic microorganisms $[1,2]$. Generally, hospital wastewaters is discharged into the publicy owned treatment works (POTWs) with or without pretreatment [1]. In POTWs, the trace contaminants could not be entirely removed by the conventional wastewater treatment technologies and then, are partially or completely discharged into the environment $[3,4]$. Among the above listed contaminants,

c) The Author(s) 2020. This article is licensed under a Creative Commons Attribution 4.0 International License, which permits use, sharing, adaptation, distribution and reproduction in any medium or format, as long as you give appropriate credit to the original author(s) and the source, provide a link to the Creative Commons licence, and indicate if changes were made. The images or other third party material in this article are included in the article's Creative Commons licence, unless indicated otherwise in a credit line to the material. If material is not included in the article's Creative Commons licence and your intended use is not permitted by statutory regulation or exceeds the permitted use, you will need to obtain permission directly from the copyright holder. To view a copy of this licence, visit http://creativeco mmons.org/licenses/by/4.0/. The Creative Commons Public Domain Dedication waiver (http://creativecommons.org/publicdomain/ zero/1.0/) applies to the data made available in this article, unless otherwise stated in a credit line to the data. 
antibiotics are always considered with principal priority concerns due to the adverse effects on human health and deteriorating natural ecosystems [5]. Antibiotics are partially absorbed in the human body and the insufficient metabolism could change the chemical structure into more polar and soluble by-products [6]. Then, the main part of antibiotics is entered into the sewerages unchanged or as an active or inactive metabolites [7]. The major concern on antibiotics is generating bacterial resistant genes in the environment [8], which could cause increase in patients treatment period and extend hospitalization time and consequently more consumption of antibiotics and finally, increasing in health care expenditures $[9,10]$. In the United States, antibioticresistant bacteria bring about at least two million cases of infection and 23,000 mortalities per year imposing an annual cost of 55-70 billion dollars [11]. According to the World Health Organization report on antimicrobial resistance surveillance system in 2014, microbial resistance is no longer a prediction for the future, and is now happening around the world and poses a serious threat to common infectious diseases. Then, without immediate and coordinated measures, the world would come back to the history before antibiotics and common infections and minor injuries could once again make happen terrible mortalities $[12,13]$. On the other hand, the residue of antibiotics could advance adverse effects on the soil ecosystem, microorganisms, and crops and finally could enter food chain through irrigation with wastewater effluents and by land applications of biosolids [14, 15]. Antibiotics have been detected in hospital wastewaters [16], influent and effluents of municipal wastewater treatment plants $[17,18]$, soil, water resources and even drinking waters [19]. Meanwhile, antibiotics and their metabolites are not completely removed by the conventional wastewater treatment processes [20]. According to the literature, various quantities have been reported for elimination of antibiotics with physico-chemical [21], biological [22], and advanced oxidation processes $[23,24]$. Removal of antibiotics by biological treatment processes are affected by the physicochemical properties of antibiotics such as water solubility, octanol/ water partitioning coefficient, and principal plant design aspects including solids and hydraulic retention times and organic loading rates $[8,25-28]$. In some studies in Italy, Iran, and China significant concentrations of ciprofloxacin $(0.64 \mu \mathrm{g} / \mathrm{l})$, clarithromycin $(0.28 \mu \mathrm{g} / \mathrm{l})$ [29], ofloxacin $(1.43 \mu \mathrm{g} / \mathrm{l})$, sulfamethoxazole $(0.54 \mu \mathrm{g} / \mathrm{l})$ [30], quinolones $(4.91 \mu \mathrm{g} / \mathrm{l})$, sulfonamide $(2.91 \mu \mathrm{g} / \mathrm{l})$, and macrolide $(0.36 \mu \mathrm{g} / \mathrm{l})$ [8] have been detected in the effluent of POTWs. Numerous studies have been conducted on the determination of concentration and fate of antibiotics in water resources and municipal and hospital wastewaters.
Also, in plentiful investigations removal efficiencies of antibiotics by treatment processes have been evaluated. Then, a systematic review on the findings of these studies seems to be necessary to provide accurate and reliable data and optimize the design concepts for wastewater treatment plant designers and municipal planners and managers and outline a road map for prioritizing the future research subjects.

\section{Objective of the review}

The review will provide evidence based data on the variety and concentration ranges of antibiotics in hospital and municipal wastewaters and water resources. Also, the review will reveal accurate removal efficiencies of wastewater and or water treatment processes in reduction of antibiotics. The results could be used as design concepts in wastewater treatment plants. Finally, the systematic literature review will address the following primary and secondary main research questions:

\section{Primary question}

1. What is the type and concentration range of antibiotics in hospital and municipal wastewaters and receiving water bodies?

2. What are the comparative efficiencies of various wastewater treatment processes in the removal of antibiotics?

The PICO elements of these questions are provided in Table 4.

\section{Secondary questions}

1. What are the most abundant antibiotic members in hospital and municipal wastewaters and water resources?

2. How much are the averages and standard deviations of the concentration of various antibiotics in the hospital or municipal wastewaters or water resources?

3. How much are the effectiveness of conventional wastewater treatment processes in removing various groups of antibiotics?

4. Which design and operational conditions could affect the efficiency of treatment processes in the removal of antibiotics?

5. What is the best available technology regarding the performance in the removal of antibiotics from wastewater and water? 


\section{Methods}

The review will be performed according to the Collaboration for Environmental Evidence (CEE) guidelines for systematic review and evidence synthesis in environmental management [31], and will be reported according to ROSES reporting standards [32]. This review protocol has been registered in the PROSPERO database. The protocol was prepared according to the ROSES form for systematic review protocol and could be find in an Additional file 1.

\section{Search strategy}

In order to determine a search strategy in electronic databases, the review team was asked to suggest the keywords using published reviews on the topic [33, 34]. In order to determine the content validity, search terms were re-reviewed by the members of the team. Then, in order to examine the maximum access to all papers related to the search terms, the initial search was conducted using selected keywords with high sensitivity in Embase, Web of Science, Science Direct, Scopus, and PubMed.

After the primary search of the papers, the first 50 articles were selected by relevance in terms of title, abstract and keyword and full text of the articles were reviewed by the colleagues to determine and finalize the search terms. After this step, the search strings have been revised to obtain an optimum level of both sensitivity and specificity. Sensitivity is the ability of a search to capture all relevant articles. Specificity refers to the ability of a search to accomplish only relevant articles and minimize irrelevant reaches. For the specificity, several repetitions of the keywords were used in search attempts until excluding a desirable level of irrelevant hits. To increase the sensitivity of the search it was later decided to broaden the scope of the search and not use any of the biases as search terms. Then, synonym terms will be applied and combined using the Boolean operator of "OR". Also, to prevent an increase in the number of unrelated articles in searching, the Boolean operator of "AND" will be used in combining the terms. The list of suggested search terms, search string, and how to use Boolean operators (AND, OR) are shown in Table 1. In addition, the asterisk (*) will be used to include the different search terms characters. The search strategy will be adjusted according to the instructions of each database.

\section{Supplemental searches}

The reference list of original and review articles found using search strategy will be skimmed to find any relevant articles. An email will also be sent to the authors whose paper information is incomplete to obtain any required information or in the case of not having access to the full text of the articles.

\section{Language}

A very high proportion of the research articles published worldwide currently appears in English. Then, this systematic review study will be limited to English articles that their full texts are available in the international databases. The period between 2010 and 2021 has been selected for the search time of published papers and reviewing the reference list in the articles.

\section{Publication databases}

The databases will be searched for relevant articles include:

- MEDLINE using PubMed (http://www.ncbi.nlm.nih. gov).

- EMBASE (http://www.embase.com).

- Web of Science Core Collection (https://webofknowl edge.com)

- Scopus (http://www.scopus.com)

- Science direct (http://www.sciencedirect.com)

\section{Assessing search comprehensiveness}

The comprehensiveness of the search strategy was examined according to the method used by Bennett et al. [35]. First, 13 relevant papers were considered as "test set" that had the highest citation and have been published in valid journals that scored as Q1 in Scimago Journal Ranking (SJR) site. Then, the bibliography of the "test set" articles was reviewed to determine if they are found through our search strategy, otherwise, the search strategy will be modified again (Table 2).

\section{Update articles}

If the process of systematic review is prolonged, the search will be updated by the same search strategies. In the new obtained articles, the duplicates will be removed and

\section{Table 1 The proposed final search string for accomplishment of the searches}

\footnotetext{
Search string

(water* OR wastewater* OR "waste-water*" OR sewage* OR effluent* OR influent* OR aqueous) AND (antibiotic* OR pharmaceutical*) AND (treatment* OR removal* OR elimination* OR reduction* OR degradation* OR mineralization*)
} 


\begin{tabular}{llr}
$\begin{array}{l}\text { Table } 2 \text { The } \\
\text { in the comprehensiveness appraisal of the search strategy }\end{array}$ \\
\hline NO & Citation & $\begin{array}{c}\text { Years } \\
\text { articles }\end{array}$ \\
\hline 1 & Rashid [36] & 2020 \\
2 & Verlicchi [29] & 2012 \\
3 & Zhang [37] & 2015 \\
4 & Rodriguez-Mozaz S [38] & 2015 \\
5 & Verlicchi [39] & 2015 \\
6 & Santos [40] & 2013 \\
7 & Gros [41] & 2013 \\
8 & Zhang [42] & 2016 \\
9 & Hu 43] & 2020 \\
10 & Cheng [44] & 2018 \\
11 & Shahmahdi [4] & 2020 \\
12 & Kovalova [45] & 2012 \\
13 & Oller [46] & 2011 \\
\hline
\end{tabular}

screening will take place according to the three levels of title, abstract and full text appraisals.

\section{Type of study}

In this systematic review, the proposed study will include all descriptive and experimental articles which survey or examine presence or removing antibiotics by treatment processes from aqueous solutions such as hospital or municipal wastewaters, surface or groundwaters, tap or drinking waters or synthetic solutions. Review articles (literature reviews, systematic reviews, and meta-analysis) and letter to editor papers will be excluded. In some of these literatures valuable information could be found. However, published articles are the main references of the books. Also, books have a lag time of editing and publishing in comparison with the articles. On the other hand, most of the books are not available electronically and manual search of non-electronic resources are very time consuming.

\section{Article screening and study eligibility criteria Screening process}

The obtained articles will be imported to a reference manager. Duplicate cases will be identified and removed. Then, the articles will be screened at three levels. Prior to the screening of the articles, a test of consistency will be performed between the reviewers to ensure the inclusion and exclusion criteria at all three levels of screening. Randomly, we will select $10 \%$ of all articles or 100 papers (whichever is greater) and two reviewers will screen the articles based on the criteria, and the consistency will be obtained using Kappa test. If the result is higher than 0.7 the consistency will be significant, otherwise, the inclusion criteria will be modified and the process will be repeated until to obtain an acceptable Kappa score. In addition to scoring, discussions will be continued between the group members to reach the highest agreement and the least disagreements.

The first level of screening will be based on the titles. The article inclusion and exclusion criteria that will be considered at level one are shown in Table 3. At the second level, the article abstract will be reviewed with additional criteria including population, intervention/exposure, comparator and the outcome based on research questions are shown in Table 4. For articles without abstract or with any unclear reason to exclude the review, it will be retained and moved to the next stage.

At the third level of screening, the exclusion criteria for the full-text review will be based on the same criteria as for the abstract level and in compliance with Collaboration for Environmental Evidence (CEE) guidelines that are presented in Table 5. At this stage, the articles will be evaluated by two reviewers and approved by the third one. Then, the last selected articles will be assessed very carefully to extract the needed data. Every reviewer will list the excluded articles along with the reasons in an

Table 3 List of exclusion/inclusion criteria at the stage of title screening

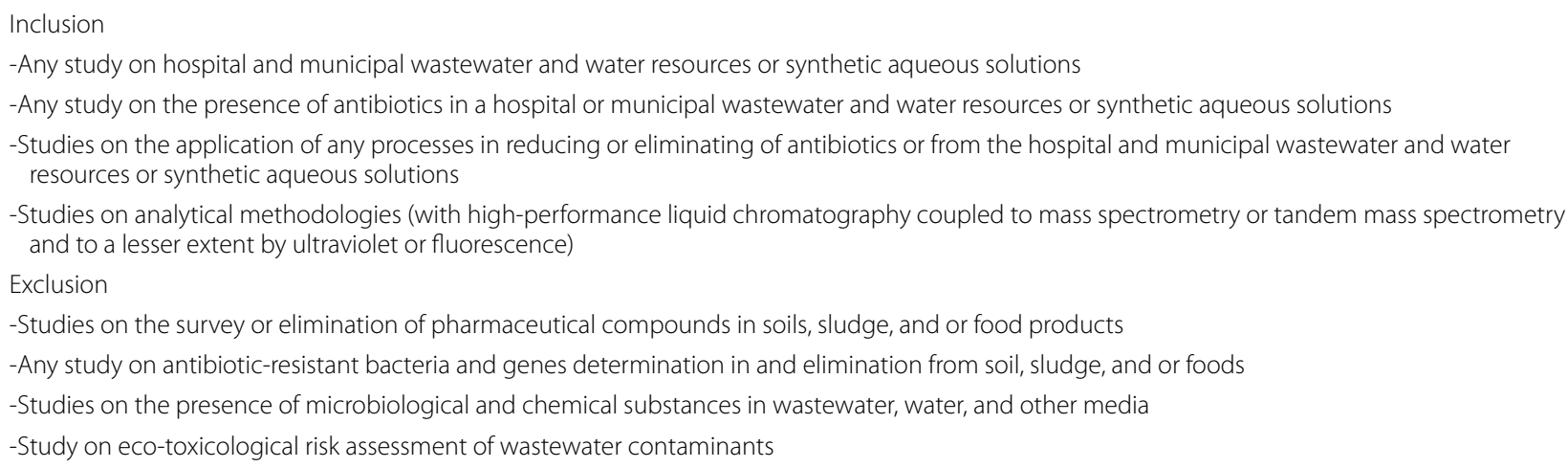


Table 4 List of exclusion/inclusion criteria at the stage of abstract screening

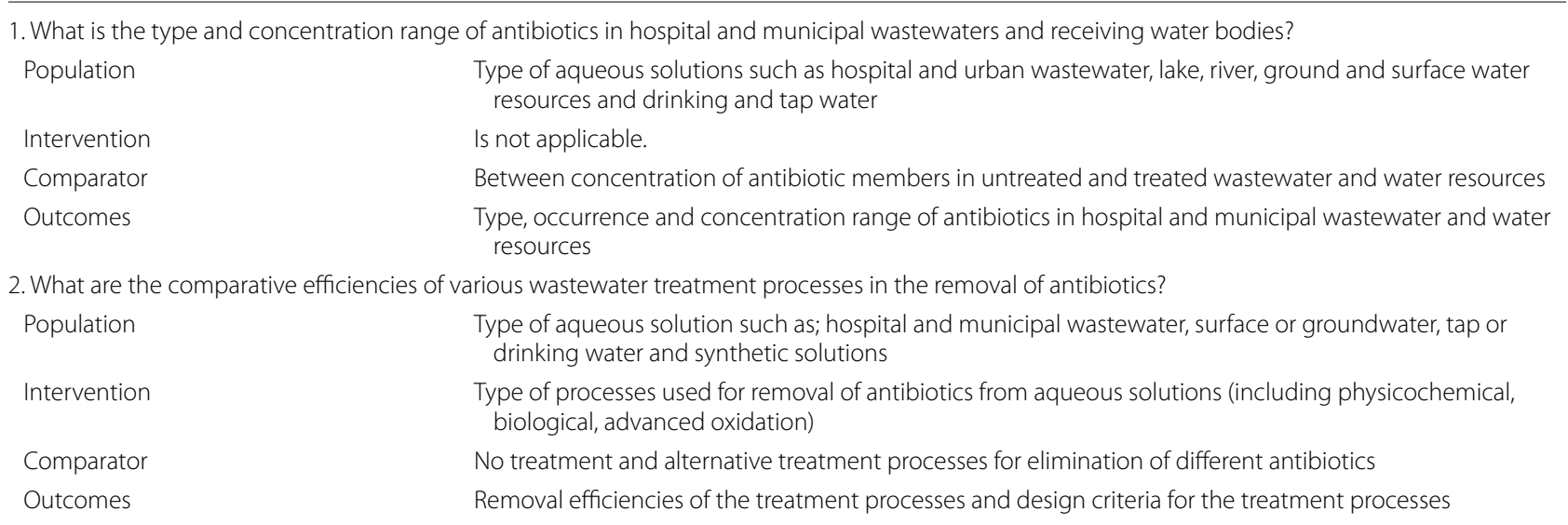

Table 5 List of exclusion criteria at the stage of full-text screening

$\checkmark$ Not on topic

$\checkmark$ No relevant population

$\checkmark$ No relevant intervention/exposure

$\checkmark$ No relevant comparator

$\checkmark$ No relevant outcome

$\checkmark$ Not quantitative

$\checkmark$ Topic specific reasons

$\checkmark$ Ambiguous data

Additional file 1 to reassessment again by the co-reviewers for any unwanted missing of important articles. In the case of unavailability of some data, the corresponding author will be contacted by email to provide the necessary information and if not, the paper will be removed.

\section{Study validity assessment}

Evaluating the quality of articles and bias will be done by combining and revising existing tools in the field of environmental sciences, including the criteria designed by Bilotta et al. which are derived from the Cochrane Collaboration's Risk of Bias Tool $[47,48]$ and the criteria defined by Schindler et al. will also be used [49]. The criteria in these tools will be reviewed by the research team based on the objectives of the study. Table 6 includes the desired criteria, assessment criteria like selection and performance, measurement of outcome, clarity and publication and the other biases. Each variable will receive a score based on the reviewers' comments. The papers will be divided into three groups based on their quality (low, medium, and high bias). Therefore, considering a range of normalized 0-100 for the quality score, studies with scores higher than 67 will be placed at high quality class, studies with scores
33-67 will be listed as a medium quality class and studies with scores less than 33 will be assigned at low quality class. Additionally, we will conduct a sensitivity analysis to seek the individual removing of each study. Then, studies that are classified with high bias will be excluded from the quantitative synthesis. It should be noticed that low quality article doesn't mean that the article is weak in its content, but the purpose of this classification is to increase the reliability of the study.

The reviewers will be provided with the necessary explanations and training before conducting the quality assessment and bias evaluation of the articles. This evaluation will be conducted on a random sample of $10 \%$ of the articles by two reviewers. Then the checklists will be compared and any disagreement on inclusion criteria at this stage will be discussed between the reviewers. Finally, all included articles will be controlled and confirmed by an expert.

\section{Data coding and extraction strategy}

A data extraction form will be used for studies that have passed the stages of screening, quality, and bias assessment. The information provided below (but not limited to) will be detailed in a datasheet:

- The bibliography of articles including authors, year of publication and type of study (bench, pilot or full scale studies, field survey)

- Type of antibiotic removal method (biological, physicochemical, absorption, membrane separation, advanced oxidation processes)

- Type of water or wastewater (hospital or municipal wastewater, surface or groundwater and synthetic solutions)

- Type of examined antibiotics 
Table 6 Bias assessment framework of articles

\begin{tabular}{|c|c|c|c|c|}
\hline Bias area & Study parameter & Characteristic & Bias assessment & Bias score \\
\hline \multirow[t]{6}{*}{$\begin{array}{l}\text { Selection and performance bias: study } \\
\text { design }\end{array}$} & \multirow[t]{6}{*}{ Sampling } & \multirow[t]{6}{*}{$\begin{array}{l}\text { Detection of antibiotic type } \\
\text { and concentration }\end{array}$} & $\begin{array}{l}\text { Total sample size > } 10 \text { (Temporal or } \\
\text { spatial) }\end{array}$ & 10 \\
\hline & & & $\begin{array}{l}\text { Total sample size < } 10 \text { (Temporal or } \\
\text { spatial) }\end{array}$ & 5 \\
\hline & & & A single sample volume $>100 \mathrm{cc}$ & 10 \\
\hline & & & A single sample volume $<100 \mathrm{cc}$ & 5 \\
\hline & & & Replication of samples & 10 \\
\hline & & & No-replication of samples & 5 \\
\hline \multirow[t]{6}{*}{$\begin{array}{l}\text { Assessment bias: measurement of } \\
\text { outcome }\end{array}$} & \multirow[t]{6}{*}{ Experimental design } & \multirow[t]{2}{*}{ Plant type } & $\begin{array}{l}\text { Full or pilot experiments with real } \\
\text { wastewater }\end{array}$ & 10 \\
\hline & & & $\begin{array}{l}\text { Bench scale experiments with synthetic } \\
\text { solution }\end{array}$ & 5 \\
\hline & & \multirow[t]{2}{*}{ Antibiotic extraction method } & Solid phase extraction & 10 \\
\hline & & & Liquid-liquid extraction & 5 \\
\hline & & \multirow[t]{2}{*}{ Antibiotic detection device } & $\begin{array}{l}\text { Gas or liquid chromatography coupled } \\
\text { with mass spectrophotometry }\end{array}$ & 10 \\
\hline & & & Gas or liquid chromatography & 5 \\
\hline \multirow[t]{4}{*}{ Bias linked to clarity and publication bias } & \multirow[t]{4}{*}{ Data analysis } & \multirow[t]{4}{*}{ Statistical analyses } & \multirow{2}{*}{$\begin{array}{l}\text { Using and describing the statistical data } \\
\text { analysis method }\end{array}$} & Yes [10] \\
\hline & & & & No $[5]$ \\
\hline & & & \multirow{2}{*}{$\begin{array}{l}\text { Clarity of the presentation of data qual- } \\
\text { ity/quantity or statistical analysis }\end{array}$} & Yes [10] \\
\hline & & & & No $[5]$ \\
\hline \multirow[t]{6}{*}{ Other biases } & & \multirow[t]{2}{*}{ Detection bias } & \multirow{2}{*}{$\begin{array}{l}\text { Having significant differences in the } \\
\text { results in before and after treatment } \\
\text { process }\end{array}$} & Yes [10] \\
\hline & & & & No [5] \\
\hline & & \multirow[t]{4}{*}{ Attrition bias } & \multirow{2}{*}{$\begin{array}{l}\text { Same sample size in before and after } \\
\text { treatment process }\end{array}$} & Yes [10] \\
\hline & & & & No [5] \\
\hline & & & \multirow{2}{*}{$\begin{array}{l}\text { Same number of samples in before and } \\
\text { after treatment process }\end{array}$} & Yes [10] \\
\hline & & & & No [5] \\
\hline
\end{tabular}

- Antibiotics extraction and detection methods and reported concentration range of antibiotics and statistical analysis

- Type, description and operation parameters of the treatment process,

- Experimental conditions (antibiotic initial concentration, reaction or exposure time, $\mathrm{pH}$, chemical dosing rate and etc.)

- Antibiotic removal efficiencies

- Detected by-products

- Removal rate of biochemical oxygen demand (BOD), chemical oxygen demand (COD) and total organic carbon (TOC)

The results of the review are displayed in graphs, figures, tables, and text. A summary of statistics is used when the raw data are presented in the articles. If the article data are ambiguous, the author will be contacted and will be required to provide explanations. In order to reduce bias and error in data reporting, two reviewers will independently extract the data, and the same manner used in the screening stage will be used to evaluate the agreement between the two reviewers. In case of disagreement, researchers will be discussed or opinion of the third reviewer will be accepted. We will first interpret and integrate the findings to reach a "bottom line" message that incorporates the strengths, weaknesses, inconsistencies, and gaps in the evidence, as well as potential moderators such as populations, study designs, and contextual factors; and we will then report this message together with a brief summary of the evidence that supports the message. Narrative synthesis works with both numeric data and qualitative data.

\section{Potential effect modifiers/reasons for heterogeneity}

Useful outcomes and data on interventions and other potential effect modifiers will be extracted from included articles and recorded by the research team. The following is a list of possible elements that can cause variations to the effects between the studies and the data will be recorded in an Additional file 1: 
- Comparator type (spatial/temporal variations, extended variety in the type of antibiotics, type of examined wastewater and water resources and etc.)

- Sampling method (sample size, randomization of sample selection, number of replicates, etc.)

- Type of antibiotics extraction and detection methods

- Variability in the type and operational parameters of the treatment processes

- Different operation parameters of the treatment process

- Various experimental conditions such as antibiotic initial concentration, reaction or exposure time

This list is not thorough, and a conclusive list of effect modifiers and causes of heterogeneity will be determined as the review proceeds.

\section{Data synthesis and presentation}

After extracting the required data from the assessed articles, narrative synthesis will include summarizing the results and presenting them in the form of tables and figures. Quantitative analysis will be performed to categorize data according to the type of antibiotics classes and performance of the various treatment processes in the elimination of antibiotics. Then, all the quantities of antibiotics that are present in the hospital and municipal wastewater and water resources will be presented as mean and standard deviation. In the absence of data on the efficacy of treatment processes for antibiotic removal, it will be calculated using antibiotic concentration at the inlet and outlet of the treatment processes. If studies show sufficient data of similar results, meta-analysis can be used to analyze the data. Random effect Meta-analysis will be conducted due to the likely range of underlying effects. If the heterogeneity exists, the source of heterogeneity will be sought by met-regression, and subgroup analyses may be performed according to the effects of variables of the studies, such as sample size and volume, type of extraction and instrumental analysis, and the type of antibiotic. A funnel plot will be used to check the publication bias.

In order to compare removal efficiency of each antibiotic amongst the treatment processes, the data will be converted into standard removal efficiency (SRE) based on equation $\mathrm{SRE}=(x-\mu) / \sigma \quad(x=$ antibiotic removal efficiency by each treatment process, $\mu=$ the average removal efficiency of antibiotic by all purification processes, and $\sigma=$ the standard deviation of removal efficiency by all treatment processes) [50]. The average SRE for each treatment option will be calculated and analyzed for significant differences in the average SREs using randomizations without replacement. This method is well suited for examining differences between study effect sizes, and has been effectively utilized to analyses similarly structured datasets exploring toxicological processes. The randomizations will be performed using Excel software, by calculating the differences in the average of all SREs among the treatment processes, and then randomly recasting the data to the different groups and recalculating the differences.

\section{Supplementary information}

Supplementary information accompanies this paper at https://doi. org/10.1186/s13750-020-00201-z.

Additional file 1. ROSES form for systematic review protocol of Diversity of antibiotics in hospital and municipal wastewaters and receiving water bodies and removal efficiency by treatment processes.

\section{Acknowledgements}

The authors acknowledge the financial and technical support provided by Research Vice Chancellor, Tabriz University of Medical Sciences, Tabriz, Iran.

\section{Authors' contributions}

The authors of the present protocol declare that they have cooperated in the idea and writing of the protocol. All authors read and approved the final manuscript.

\section{Funding}

Tabriz University of Medical Sciences through its Research Vice Chancellor funded the systematic review and meta-analysis protocol described here.

\section{Availability of data and materials}

Not applicable.

\section{Ethics approval and consent to participate}

Not applicable.

\section{Consent for publication}

Not applicable.

\section{Competing interests}

The authors declare that there is no conflict of interest in the present study.

\section{Author details}

${ }^{1}$ Health and Environment Research Center, Tabriz University of Medical Sciences, Tabriz, Iran. ${ }^{2}$ Department of Biostatistics and Epidemiology, School of Health, Tabriz University of Medical Sciences, Tabriz, Iran. ${ }^{3}$ Faculty of Health, Tabriz University of Medical Sciences, Tabriz, Iran.

Received: 18 January 2020 Accepted: 25 August 2020

Published online: 11 September 2020

\section{References}

1. Arslan A, Veli S, Bingöl D. Use of response surface methodology for pretreatment of hospital wastewater by O3/UV and O3/UV/H2O2 processes. Sep Purif Technol. 2014;132:561-7

2. Magdaleno A, Juárez ÁB, Dragani V, Saenz ME, Paz M, Moretton J. Ecotoxicological and genotoxic evaluation of Buenos Aires city (Argentina) hospital wastewater. J Toxicol. 2014;2014:248461.

3. Chonova T, Keck F, Labanowski J, Montuelle B, Rimet F, Bouchez A. Separate treatment of hospital and urban wastewaters: a real scale comparison of effluents and their effect on microbial communities. Sci Total Environ. 2016;542:965-75.

4. Shahmahdi N, Dehghanzadeh R, Aslani H, Shokouhi SB. Performance evaluation of waste iron shavings (Fe0) for catalytic ozonation in removal 
of sulfamethoxazole from municipal wastewater treatment plant effluent in a batch mode pilot plant. Chem Eng J. 2020;383:123093.

5. Álvarez-Torrellas S, Peres J, Gil-Álvarez V, Ovejero G, García J. Effective adsorption of non-biodegradable pharmaceuticals from hospital wastewater with different carbon materials. Chem Eng J. 2017;320:319-29.

6. Kimosop SJ, Getenga Z, Orata F, Okello V, Cheruiyot J. Residue levels and discharge loads of antibiotics in wastewater treatment plants (WWTPs), hospital lagoons, and rivers within Lake Victoria Basin, Kenya. Environ Monit Assess. 2016;188(9):532

7. Sousa JC, Ribeiro AR, Barbosa MO, Pereira MFR, Silva AM. A review on environmental monitoring of water organic pollutants identified by EU guidelines. J Hazard Mater. 2018;344:146-62.

8. Yan C, Yang Y, Zhou J, Liu M, Nie M, Shi H, et al. Antibiotics in the surface water of the Yangtze Estuary: occurrence, distribution and risk assessment. Environ Pollut. 2013;175:22-9.

9. Fekadu S, Merid Y, Beyene H, Teshome W, Gebre-Selassie S. Assessment of antibiotic-and disinfectant-resistant bacteria in hospital wastewater, south Ethiopia: a cross-sectional study. J Infect Dev Count. 2015;9(02):149-56.

10. Organization WH. Global action plan on antimicrobial resistance. 2015. 2017.

11. Li B, Webster TJ. Bacteria antibiotic resistance: new challenges and opportunities for implant-associated orthopedic infections. J Orthop Res. 2018;36(1):22-32.

12. Organization WH. Antimicrobial resistance: global report on surveillance. Geneva: World Health Organization; 2014.

13. Lucas D, Badia-Fabregat M, Vicent T, Caminal G, Rodríguez-Mozaz S, Balcázar JL, et al. Fungal treatment for the removal of antibiotics and antibiotic resistance genes in veterinary hospital wastewater. Chemosphere. 2016;152:301-8.

14. Wei X, Wu S, Nie X, Yediler A, Wong MH. The effects of residual tetracycline on soil enzymatic activities and plant growth. J Environ Sci Health B. 2009:44(5):461-71.

15. Meena V, Dotaniya M, Saha J, Patra A. Antibiotics and antibiotic resistant bacteria in wastewater: impact on environment, soil microbial activity and human health. Afr J Microbiol Res. 2015;9(14):965-78.

16. Dinh Q, Moreau-Guigon E, Labadie P, Alliot F, Teil M-J, Blanchard M, et al. Fate of antibiotics from hospital and domestic sources in a sewage network. Sci Total Environ. 2017;575:758-66.

17. Tylová T, Flieger M, Olšovská J. Determination of antibiotics in influents and effluents of wastewater-treatment-plants in the Czech Republicdevelopment and application of the SPE and a UHPLC-ToFMS method. Anal Methods. 2013;5(8):2110-8.

18. Vergeynst L, Haeck A, De Wispelaere P, Van Langenhove H, Demeestere K. Multi-residue analysis of pharmaceuticals in wastewater by liquid chromatography-magnetic sector mass spectrometry: method quality assessment and application in a Belgian case study. Chemosphere. 2015;119:S2-8.

19. Gothwal R, Shashidhar T. Antibiotic pollution in the environment: a review. Clean-Soil Air Water. 2015;43(4):479-89.

20. Azanu D, Styrishave B, Darko G, Weisser JJ, Abaidoo RC. Occurrence and risk assessment of antibiotics in water and lettuce in Ghana. Sci Total Environ. 2018:622-623:293-305.

21. Suarez S, Lema JM, Omil F. Pre-treatment of hospital wastewater by coagulation-flocculation and flotation. Bioresour Technol. 2009;100(7):2138-46.

22. Zhou L-J, Ying G-G, Liu S, Zhao J-L, Yang B, Chen Z-F, et al. Occurrence and fate of eleven classes of antibiotics in two typical wastewater treatment plants in South China. Sci Total Environ. 2013;452-453:365-76.

23. Tang J, Wang J. Metal organic framework with coordinatively unsaturated sites as efficient Fenton-like catalyst for enhanced degradation of sulfamethazine. Environ Sci Technol. 2018;52(9):5367-77.

24. Liu Y, Fan Q, Wang J. Zn-Fe-CNTs catalytic in situ generation of $\mathrm{H}_{2} \mathrm{O} 2$ for Fenton-like degradation of sulfamethoxazole. J Hazard Mater. 2018;342:166-76.

25. Bartrons M, Peñuelas J. Pharmaceuticals and personal-care products in plants. Trends Plant Sci. 2017;22(3):194-203.

26. Gao L, Shi Y, Li W, Niu H, Liu J, Cai Y. Occurrence of antibiotics in eight sewage treatment plants in Beijing. China. Chemosphere. 2012;86(6):665-71.

27. Perini JAL, Tonetti AL, Vidal C, Montagner CC, Nogueira RFP. Simultaneous degradation of ciprofloxacin, amoxicillin, sulfathiazole and sulfamethazine, and disinfection of hospital effluent after biological treatment via photo-Fenton process under ultraviolet germicidal irradiation. Appl Catal B-Environ. 2018;224:761-71.

28. Kafaei R, Papari F, Seyedabadi M, Sahebi S, Tahmasebi R, Ahmadi M, et al. Occurrence, distribution, and potential sources of antibiotics pollution in the water-sediment of the northern coastline of the Persian Gulf. Iran. Sci Total Environ. 2018;627:703-12

29. Verlicchi P, Al Aukidy M, Galletti A, Petrovic M, Barceló D. Hospital effluent: investigation of the concentrations and distribution of pharmaceuticals and environmental risk assessment. Sci Total Environ. 2012;430:109-18.

30. Shokoohi R, Ghobadi N, Godini K, Hadi M, Atashzaban Z. Antibiotic detection in a hospital wastewater and comparison of their removal rate by activated sludge and earthworm-based vermifilteration: environmental risk assessment. Process Saf Environ Prot. 2020;134:169-77.

31. Pullin A, Frampton G, Livoreil B, Petrokofsky G. Guidelines and standards for evidence synthesis in environmental management. Collaboration Environ Evidence. 2018

32. Haddaway N, Macura B, Whaley P, Pullin A. ROSES for systematic review protocols. Version 1.0. 2017.

33. Douziech M, Conesa IR, Benítez-López A, Franco A, Huijbregts M, van Zelm R. Quantifying variability in removal efficiencies of chemicals in activated sludge wastewater treatment plants-a meta-analytical approach. Environ Sci Process Impacts. 2018;20(1):171-82.

34. Lautz L, Struijs J, Nolte T, Breure A, Van der Grinten E, Van de Meent D, et al. Evaluation of SimpleTreat 4.0: simulations of pharmaceutical removal in wastewater treatment plant facilities. Chemosphere. 2017;168:870-6.

35. Bennett MG, Schofield KA, Lee SS, Norton SB. Response of chlorophyll a to total nitrogen and total phosphorus concentrations in lotic ecosystems: a systematic review protocol. Environ Evid. 2017;6(1):18.

36. Rashid A, Mazhar HS, Zeng Q, Kiki C, Yu C-P, Sun Q. Simultaneous analysis of multiclass antibiotic residues in complex environmental matrices by liquid chromatography with Tandem Quadrupole Mass Spectrometry. J Chromatogr B. 2020;1145:122103.

37. Zhang Q-Q, Ying G-G, Pan C-G, Liu Y-S, Zhao J-L. Comprehensive evaluation of antibiotics emission and fate in the river basins of China: source analysis, multimedia modeling, and linkage to bacterial resistance. Environ Sci Technol. 2015;49(11):6772-82.

38. Rodriguez-Mozaz S, Chamorro S, Marti E, Huerta B, Gros M, Sànchez-Melsió $A$, et al. Occurrence of antibiotics and antibiotic resistance genes in hospital and urban wastewaters and their impact on the receiving river. Water Res. 2015;69:234-42.

39. Verlicchi P, Al Aukidy M, Zambello E. Occurrence of pharmaceutical compounds in urban wastewater: removal, mass load and environmental risk after a secondary treatment-a review. Sci Total Environ. 2012;429:123-55.

40. Santos LH, Gros M, Rodriguez-Mozaz S, Delerue-Matos C, Pena A, Barceló $D$, et al. Contribution of hospital effluents to the load of pharmaceuticals in urban wastewaters: identification of ecologically relevant pharmaceuticals. Sci Total Environ. 2013;461:302-16.

41. Gros M, Rodríguez-Mozaz S, Barceló D. Rapid analysis of multiclass antibiotic residues and some of their metabolites in hospital, urban wastewater and river water by ultra-high-performance liquid chromatography coupled to quadrupole-linear ion trap tandem mass spectrometry. J Chromatogr A. 2013;1292:173-88.

42. Zhang R, Yang Y, Huang C-H, Zhao L, Sun P. Kinetics and modeling of sulfonamide antibiotic degradation in wastewater and human urine by UV/H2O2 and UV/PDS. Water Res. 2016;103:283-92.

43. Hu D, Min H, Wang H, Zhao Y, Cui Y, Wu P, et al. Performance of an up-flow anaerobic bio-electrochemical system (UBES) for treating sulfamethoxazole (SMX) antibiotic wastewater. Bioresour Technol. 2020;305:123070.

44. Cheng D, Ngo HH, Guo W, Liu Y, Chang SW, Nguyen DD, et al. Anaerobic membrane bioreactors for antibiotic wastewater treatment: performance and membrane fouling issues. Bioresour Technol. 2018;267:714-24.

45. Kovalova L, Siegrist H, Singer H, Wittmer A, McArdell CS. Hospital wastewater treatment by membrane bioreactor: performance and efficiency for organic micropollutant elimination. Environ Sci Technol. 2012;46(3):1536-45.

46. Oller I, Malato S, Sánchez-Pérez J. Combination of advanced oxidation processes and biological treatments for wastewater decontamination-a review. Sci Total Environ. 2011;409(20):4141-66. 
47. Bilotta GS, Milner AM, Boyd IL. Quality assessment tools for evidence from environmental science. Environ Evid. 2014;3(1):14.

48. Higgins JP, Altman DG, Gøtzsche PC, Jüni P, Moher D, Oxman AD, et al. The Cochrane collaboration's tool for assessing risk of bias in randomised trials. BMJ. 2011;343:d5928.

49. Schindler S, Bayliss HR, EssI F, Rabitsch W, Follak S, Pullin AS. Effectiveness of management interventions for control of invasive Common ragweed Ambrosia artemisiifolia: a systematic review protocol. Environ Evid. 2016;5(1):11.
50. Melvin SD, Leusch FD. Removal of trace organic contaminants from domestic wastewater: a meta-analysis comparison of sewage treatment technologies. Environ Int. 2016;92-93:183-8.

\section{Publisher's Note}

Springer Nature remains neutral with regard to jurisdictional claims in published maps and institutional affiliations.
Ready to submit your research? Choose BMC and benefit from:

- fast, convenient online submission

- thorough peer review by experienced researchers in your field

- rapid publication on acceptance

- support for research data, including large and complex data types

- gold Open Access which fosters wider collaboration and increased citations

- maximum visibility for your research: over $100 \mathrm{M}$ website views per year

At BMC, research is always in progress.

Learn more biomedcentral.com/submissions 